\title{
RESERVES ESTIMATION OF A MARBLE QUARRY USING QUALITY INDICATORS
}

\author{
Kapageridis I. ${ }^{1}$ and Albanopoulos C. $^{2}$ \\ ${ }^{1}$ Technological Educational Institute of Western Macedonia, Department of Environmental and \\ Pollution Control Engineering, Koila, 50100, Kozani, Greece, ikapa@teiwm.gr \\ ${ }^{2}$ Iktinos Hellas SA, $11^{\text {th }}$ Aeshilou St., 66100,Drama, Greece, albanopoulos@iktinos.gr
}

\begin{abstract}
The use of standard estimation and modelling software tools in estimating marble quarry reserves poses a number of challenges. Marble quarry reserves are based on marble quality categories, almost unique for each quarry/deposit considered. These categories represent visual and physical aspects of marble such as colour, texture and fractures. Classification of marble to one of the categories is performed by experienced personnel and is based on samples much smaller in area than the blocks of marble which are potentially exploited. The available information is, also, mostly qualitative leading to further complications in the application of geomathematical estimation methods. The estimation of marble reserves described in this paper is based on interpolating quality indicator values from drillhole and quarry face samples to blocks in three dimensions. The procedure is applied in all working quarries of Iktinos Hellas SA and is based on Maptek Vulcan Quarry Modeller, a mine planning package adapted for quarrying. Its application and results is demonstrated using a case study from one of the quarries in NE Greece.
\end{abstract}

Keywords: inverse distance weighting, quality indicators, reserves estimation, marble quarrying.

\section{Пєрі́ $\eta \psi \eta \eta$}

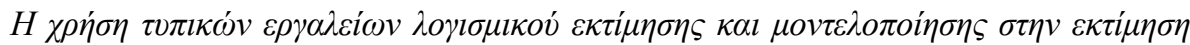

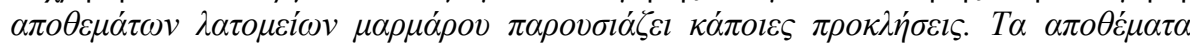

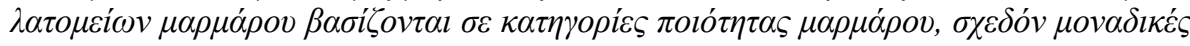

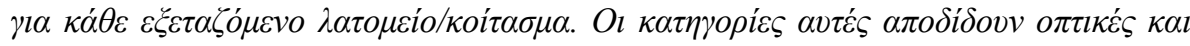


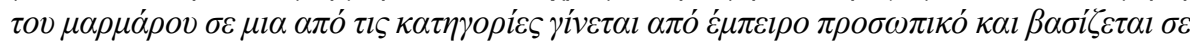

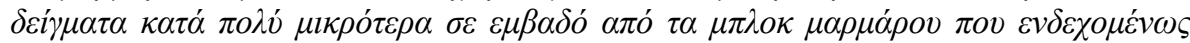

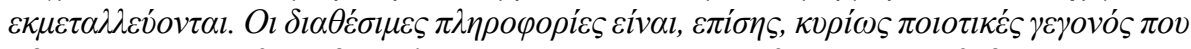

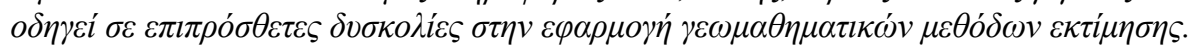

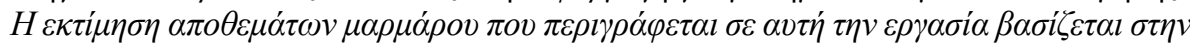

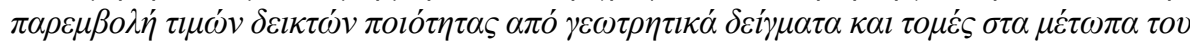

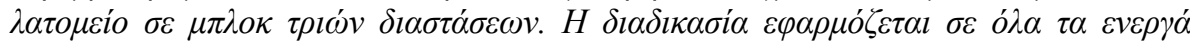

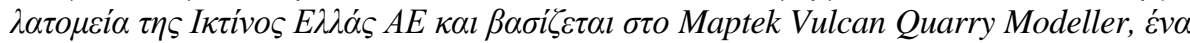

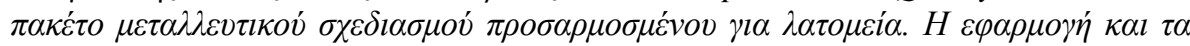

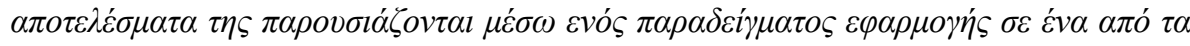

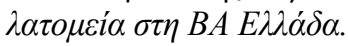

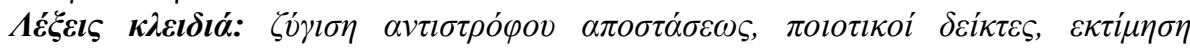

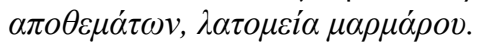




\section{Introduction}

The reserves estimation procedure discussed in this paper concerns the Platanotopos quarry of Iktinos Hellas SA (Figure 1) - similar procedures are applied to the other quarries of the company. Specialised mine planning software (Maptek Vulcan Quarry Modeller) was used in all estimation and reporting stages. Data was provided by Iktinos Hellas SA personnel, including samples quality characterisation. A technical report was issued on behalf of Iktinos Hellas SA (Kapageridis, 2015). Similar computerised estimation efforts are reported by Forlani et al., 2000, Careddu et al., 2010, and Abdollahisharif et al., 2012.

\subsection{Location}

The quarry area is located in the Municipal District of Platanotopos of the Piereon Municipality of Kavala Prefecture, approximately $1.5 \mathrm{~km}$ NNE of the Platanotopos village and $2 \mathrm{~km} \mathrm{SW}$ of the Mesoropi village (Figure 1). The quarry area under exploration is $88.649 \mathrm{~m}^{2}$. The quarry area is in public forest land between 380 and 540m elevation covered by bushes, and administered by Kavala Prefecture Authorities and Kavala Forest Inspection Authorities.

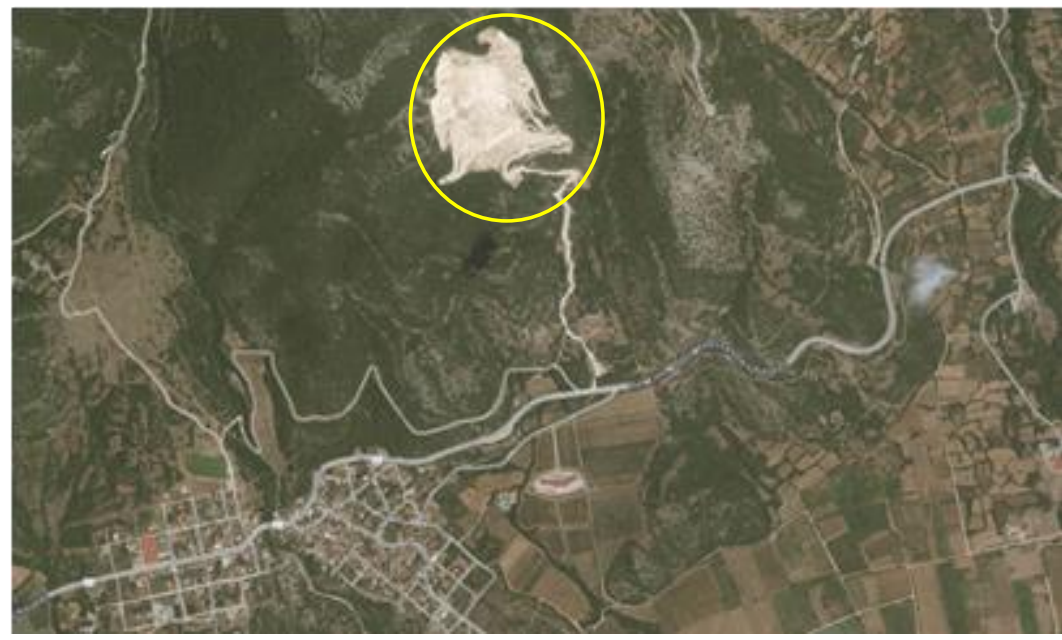

Figure 1 - Location of Platanotopos quarry near Platanotopos village.

\subsection{Geological Background and Production History}

The area belongs to the Rodopi Metamorphic Mass, extending from Thrace to part of Central Macedonia, with characteristic metamorphic geological formations and in particular marble horizons (metamorphic limestones) with gneissic background. Generally, the wider area is characterised by horizons and outcrops of white - semi-white and grey marbles, locally subject to quarrying. In the quarry area we meet calcitic and dolomitic marbles, gneiss and gneissic schists. Calcitic marbles, gneiss and gneissic schists have no use and are not targeted for quarrying.

Interest is focused on dolomitic marbles which are enclosed and protected as a lens by alternating gneissic schist layers and calcitic marbles. The horizons orientation is constant with a bearing NNWSSE and dipping between $25^{\circ}-30^{\circ}$ ESE. As already mentioned, marbles in the area are lens-like white dolomitic microcrystallic rocks (marbles). They are characterised as solid white fine grained, with evident spider net fractures which are red-yellow as they are filled with iron oxides and hydroxides.

This rare combination of white fine grained marble which is fractured and filled with secondary material which gives back the cohesion to the marble, constitutes this dolomitic appearance particularly interesting for quarrying. Marbles are solid and allow recovery of large healthy volumes, raising the level of recovery of the quarry and limiting the production of waste material. Close to 
the surface, the marble deposit is covered by a weathered layer of marble, 1-2m thick, which has a low recovery factor for marketable marble.

Given the geological, mineralogical, and climate characteristics and the quarrying equipment of the quarry, production is scheduled for $7000-10000 \mathrm{~m}^{3}$ per annum and at this rate, the life of the quarry is estimated at 15 years. Marbles extracted are known as Golden Spider and are characterised as fine grain white dolomitic marble with spider net red-yellow fractures, filled with iron oxides and hydroxides (Figure 2). They present very good physical and mechanical properties and can take very fine polishing (Table 1). Historical production of the quarry is given in Table 2.

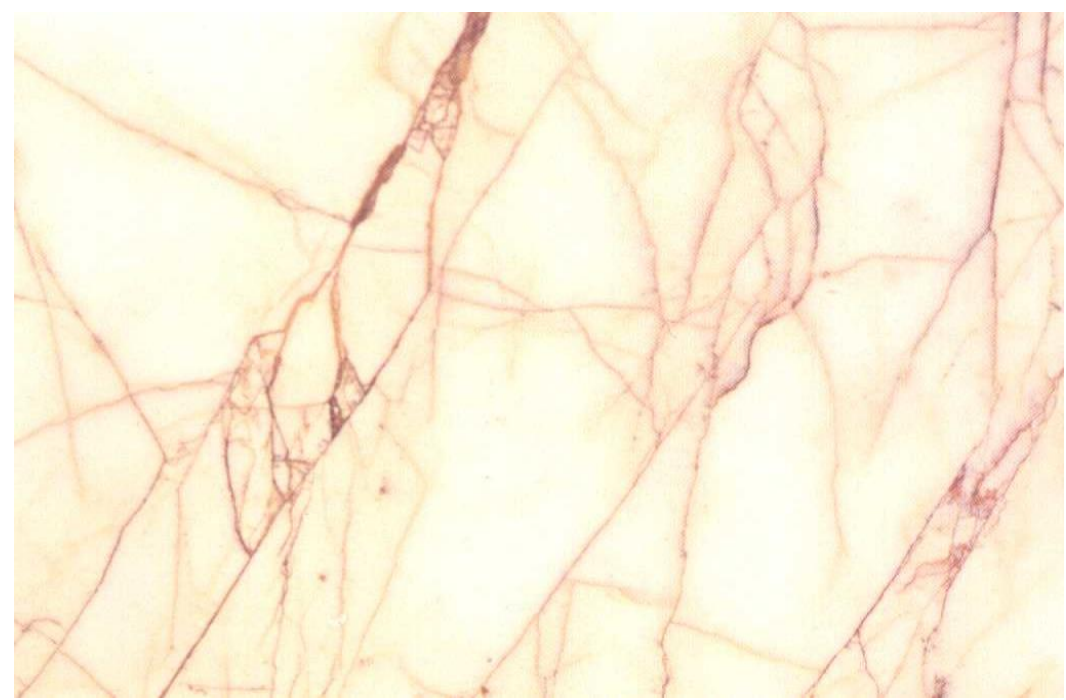

Figure 2 - Appearance of marble volumes of Platanotopos quarry.

Table 1 - Physical and chemical properties of marble from Platanotopos quarry.

\begin{tabular}{|l|c|l|c|}
\hline Specific gravity & 2.850 & $\begin{array}{l}\text { Bending strength (dry condition) } \\
\text { DIN 52112 }\end{array}$ & 11.31 \\
\hline $\begin{array}{l}\text { Open porosity factor wt\% DIN } \\
52102\end{array}$ & 0.60 & $\begin{array}{l}\text { Bending strength Mpa** (wet } \\
\text { condition) DIN 52112 }\end{array}$ & 8.25 \\
\hline Absorption factor wt\% DIN 52103 & 0.21 & $\begin{array}{l}\text { Compressive strength after } \\
\text { freezing and thaw cycles }\end{array}$ & 81.25 \\
\hline $\begin{array}{l}\text { Elasticity } \\
\text { Gpa ASTM C-170 }\end{array}$ & 42 & $\begin{array}{l}\text { Abrasion wearing } \\
\text { mm DIN 52108 }\end{array}$ & 2.06 \\
\hline $\begin{array}{l}\text { Compressive strength } \\
\text { N/mm } \text { (d** (dry condition)DIN 52105 }^{2}\end{array}$ & 120.6 & $\begin{array}{l}\text { Impact strength } \\
\text { cm UNI-U 32.07.248.0 }\end{array}$ & 29 \\
\hline $\begin{array}{l}\text { Compressive strength } \\
\text { N/mm }\end{array}$ (** (wet condition) DIN & 146.3 & $* * 1 \mathrm{MPa}=1 \mathrm{~N} / \mathrm{mm}^{2}=10.2 \mathrm{kp} / \mathrm{cm}^{2}$ & \\
\hline
\end{tabular}

\section{Marble Blocks Quality Characterisation}

\subsection{Colour and Texture}

Quality grading of Golden Spider marble is initially based on colour and in the following categories: $\mathrm{G}$ - Golden, Y - Yellow, R - Red. Grading based on spider texture is in one of 4 categories as described in the following table. Colour and texture combinations are presented in Figure 3. 
Table 2 - Production history of Platanotopos quarry between 2010-2014.

\begin{tabular}{|c|c|c|c|c|c|c|c|c|c|c|}
\hline & \multicolumn{2}{|c|}{2014} & \multicolumn{2}{|c|}{2013} & \multicolumn{2}{|c|}{2012} & \multicolumn{2}{|c|}{2011} & \multicolumn{2}{|c|}{2010} \\
\hline & $\mathbf{m}^{3}$ & $\%$ & $\mathbf{m}^{3}$ & $\%$ & $\mathbf{m}^{3}$ & $\%$ & $\mathbf{m}^{3}$ & $\%$ & $\mathbf{m}^{3}$ & $\%$ \\
\hline Extraction & 77,617 & & 92,668 & & 89,929 & & 73,533 & & 34,618 & \\
\hline Production & 13,494 & 17 & 20,657 & 22 & 19,905 & 22 & 21,151 & 29 & 13,409 & 39 \\
\hline A1 & 353 & 3 & 915 & 5 & 01 & 5 & 1367 & & & \\
\hline A2 & 1,835 & 14 & 2,136 & 10 & 01 & 5 & 7 & 6 & 0 & 10 \\
\hline AB & 3,423 & 25 & 3,981 & 19 & 4,684 & 24 & 5,135 & 24 & 4,100 & 31 \\
\hline B & 7,246 & 54 & 11,509 & 56 & 10,011 & 50 & 8,833 & 42 & 5,630 & 42 \\
\hline BB & 636 & 5 & 2,116 & 10 & 4,196 & 21 & 5,816 & 27 & 2,390 & 18 \\
\hline
\end{tabular}

Table 3 - Volume texture categories of Platanotopos marbles.

\begin{tabular}{|l|l|}
\hline $\mathbf{1}$ & Classic Spider, even net, clear background (classic type) \\
\hline $\mathbf{2}$ & Relatively even spider with local strong concentrations (logs), or unclearly constructed \\
\hline $\mathbf{3}$ & Dense spider, or many continuous brown lines, (heavy type) \\
\hline $\mathbf{4}$ & Absence of spider, many white parts or with minimum net, (white type) \\
\hline
\end{tabular}

\subsection{Volume Defects}

Based on defects (fractures, dendrite zones, brown lines, discolourings or marks etc.) each volume is classified using the 4 categories in Table 4 and final volume quality is assigned according to Table 5 .

Table 4 - Categories based on defects of Platanotopos marble.

\begin{tabular}{|c|l|}
\hline $\mathbf{1}$ & $\begin{array}{l}\text { Solid volume with no evident defects or defects to less than } 10 \% \text { of each slab which } \\
\text { is handled with a }-3 \% \text { or }-6 \% \text { discount }\end{array}$ \\
\hline $\mathbf{2}$ & One or two defects up to $20-25 \%$ of each slab \\
\hline $\mathbf{3}$ & Defects up to $30-35 \%$ of each slab \\
\hline $\mathbf{4}$ & Defects up to $50 \%$ of each slab \\
\hline
\end{tabular}

Table 5 - Platanotopos marble quality based on defects and texture/colour categories.

\begin{tabular}{|l|l|l|l|l|}
\hline $\begin{array}{l}\text { Rectangular (Length } \\
>180, \text { Height }>120)\end{array}$ & $\mathbf{1}-$ No defects & $\begin{array}{l}\mathbf{2}-\text { Defects } 25- \\
35 \% \text { of each }\end{array}$ & $\begin{array}{l}\text { 3 - Defects } 25- \\
35 \% \text { of each }\end{array}$ & $\begin{array}{l}\text { 4 - Defects 35- } \\
50 \% \text { of each }\end{array}$ \\
\hline Classic type 1 & $1-1=\mathrm{A} 1$ & $1-2=\mathrm{A} 2$ & $1-3=\mathrm{AB}$ & $1-4=\mathrm{B}$ \\
\hline Standard type 2 & $2-1=\mathrm{A} 2$ & $2-2=\mathrm{AB}$ & $2-3=\mathrm{B}$ & $2-4=\mathrm{BB}$ \\
\hline Heavy type 3 & $3-1=\mathrm{AB}$ & $3-2=\mathrm{B}$ & $3-3=\mathrm{BB}$ & $3-4=\mathrm{BB}$ \\
\hline White type 4 & $4-1=\mathrm{B}$ & $4-2=\mathrm{BB}$ & $4-3=\mathrm{BB}$ & $4-3=\mathrm{BB}$ \\
\hline
\end{tabular}




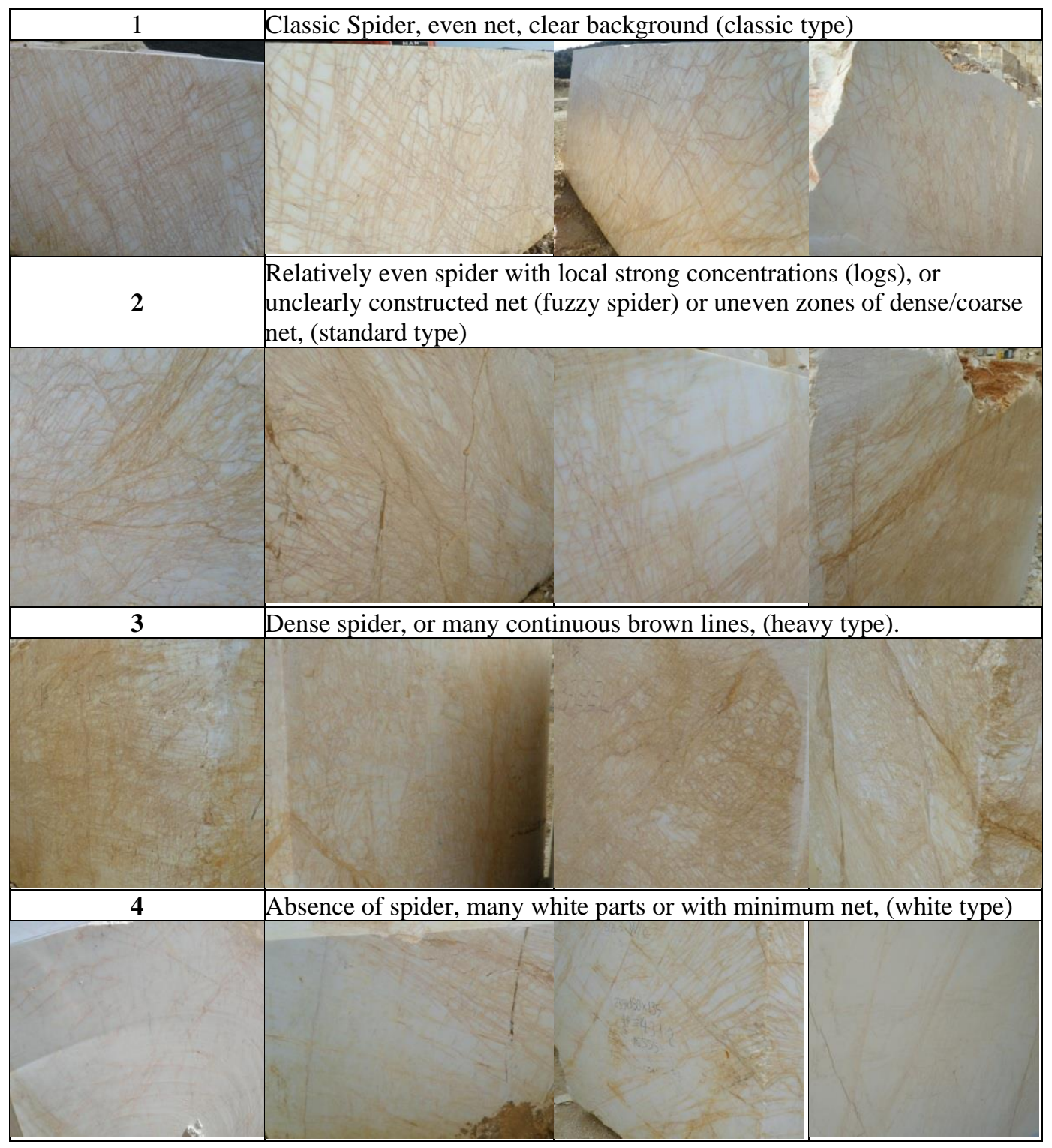

Figure 3 - Colour and texture categories of Platanotopos marbles.

\section{Reserves Estimation Data}

Data used in the reserves estimation of each quarry includes the original as well as the current topography of the quarry area based on the quarrying activities up to the date of the study. It also includes diamond drillhole samples and sections on quarry faces, which are analysed per meter as to the marble quality characteristics. A separate data folder was created for quarry with a separate database for topographical/vector data and one for drillhole/section data. An effort was made to maintain a systematic naming of all files of databases and models created during modelling and estimation. Topographical data were provided in AutoCAD ${ }^{\mathrm{TM}}$ (DWG, DXF) file format and were imported to Maptek Vulcan Quarry Modeller software and stored to appropriate layers. Drillhole data were provided in Microsoft Excel $^{\mathrm{TM}}$ file format and were imported to specialised samples 
databases in Maptek Vulcan Quarry Modeller. In the following paragraphs we discuss briefly the data provided for each quarry.

\subsection{Topographical Data}

For the Platanotopos quarry, two layers were provided with the minor and major contours every 4 and 20 meters respectively. The exploitation limits were given as a separate layer as shown in Figure 4. The contours covered an area much larger than the quarry area and had very good detail, suitable for reserves estimation. The current morphology of the quarry was also provided in two separate layers for crests and toes.

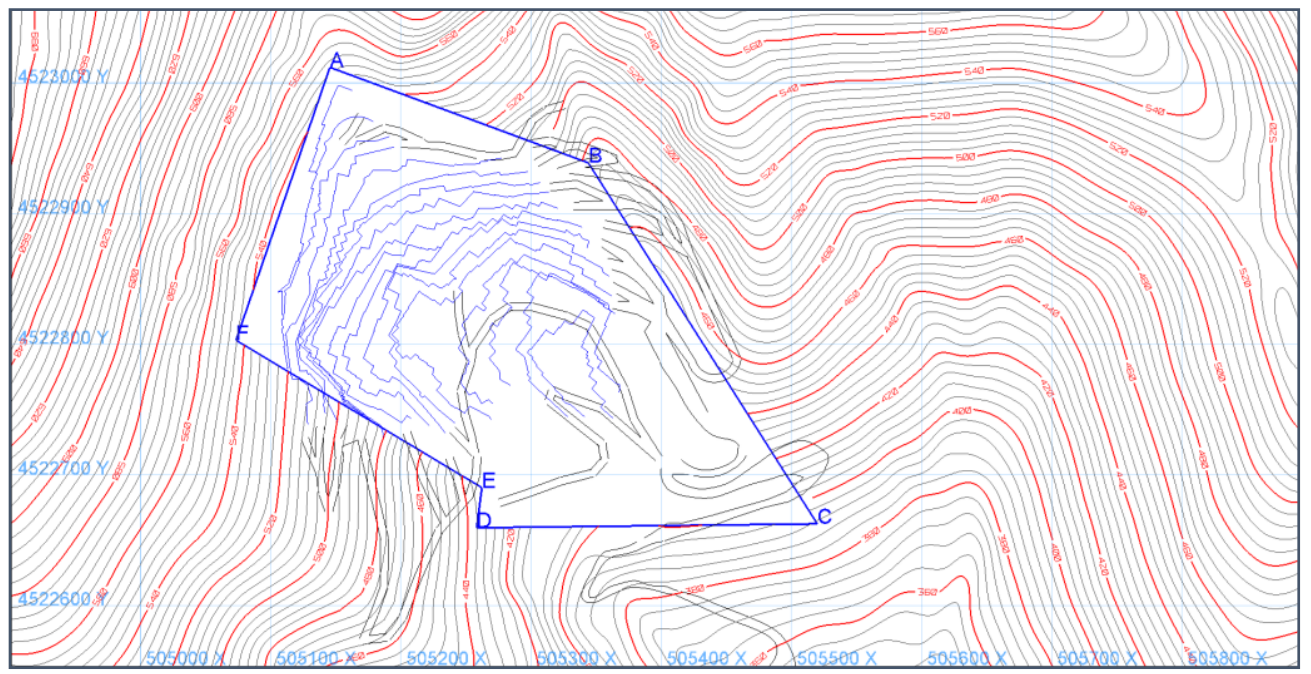

Figure 4 - Original topography contours, current pit and exploitation limits of the Platanotopos quarry.

\subsection{Drillholes and Quarry Face Sections}

A total of 92 drillholes and sections were provided for the Platanotopos quarry (47 sections and 45 drillholes), giving a total of 1,684 one-meter samples used in reserves estimation of the quarry. This data covers sufficiently the space of the estimated final excavation as show in the following figure. The data was validated using the software for collar location and overlapping intervals.

\subsection{Quarry Volumetric Model}

The estimated volume of the final excavation was designed per bench (level) starting from the existing quarry morphology. The design of each of the 16 benches was modelled as a solid triangulation which was used in reserves estimation (Figure 6). These solids were visually checked and validated using triangulation topology checks (self-crossing, opening, inconsistencies) to ensure that they can be used for valid volumetric calculations.

\section{Methodology}

\subsection{Samples Database Processing}

The drillhole and section samples database was configured with extra fields to allow the interpolation of arithmetic values in space. Specifically, fields were added which represent the different marble qualities based on original colour, texture, fracture and tectonism fields. These fields take only two values, 0 or 1 , based on if whether the specific sample belongs or not to the particular marble quality, which is based on criteria which are specific for each quarry. As shown in 
Figure 7, at the Platanotopos quarry, if a sample has lithology value LITHO = "SPIDER" and spider type SPTYP $=1$ and fractures BACKRO $=1$ then it belongs to quality A1.

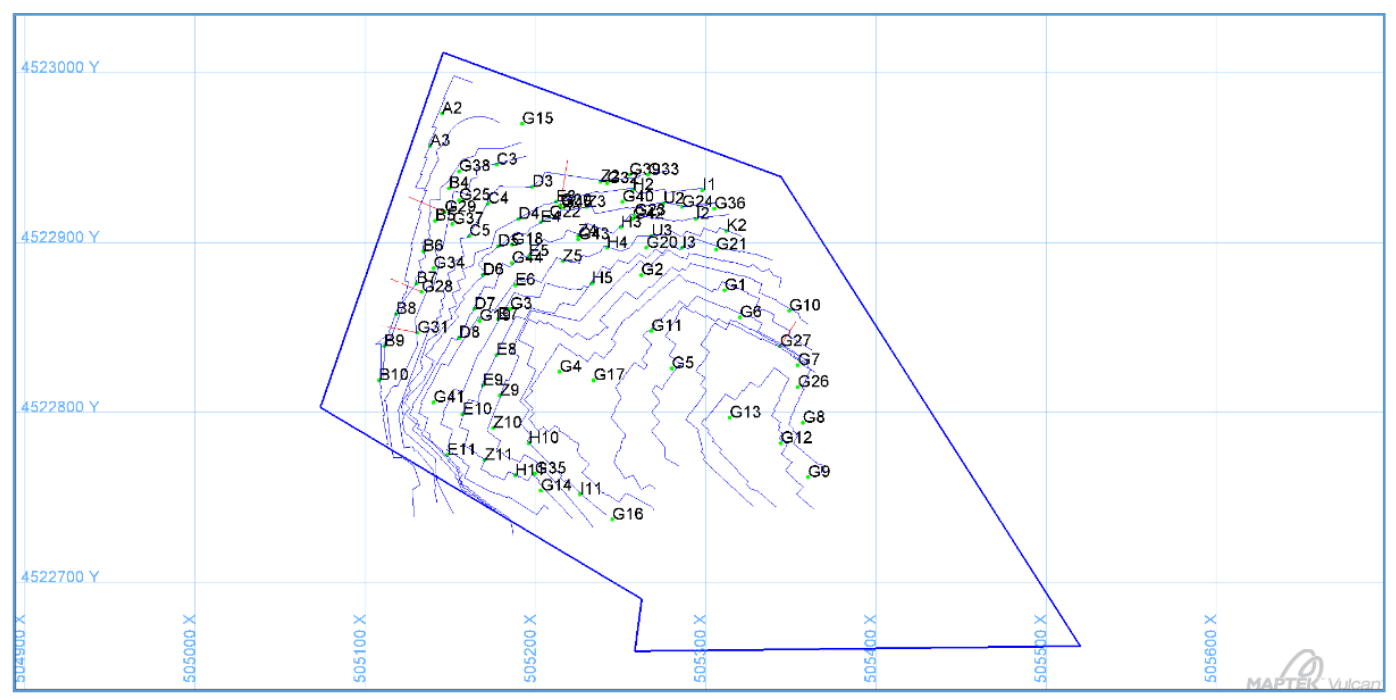

Figure 5 - Plan view of drillhole and face section locations.

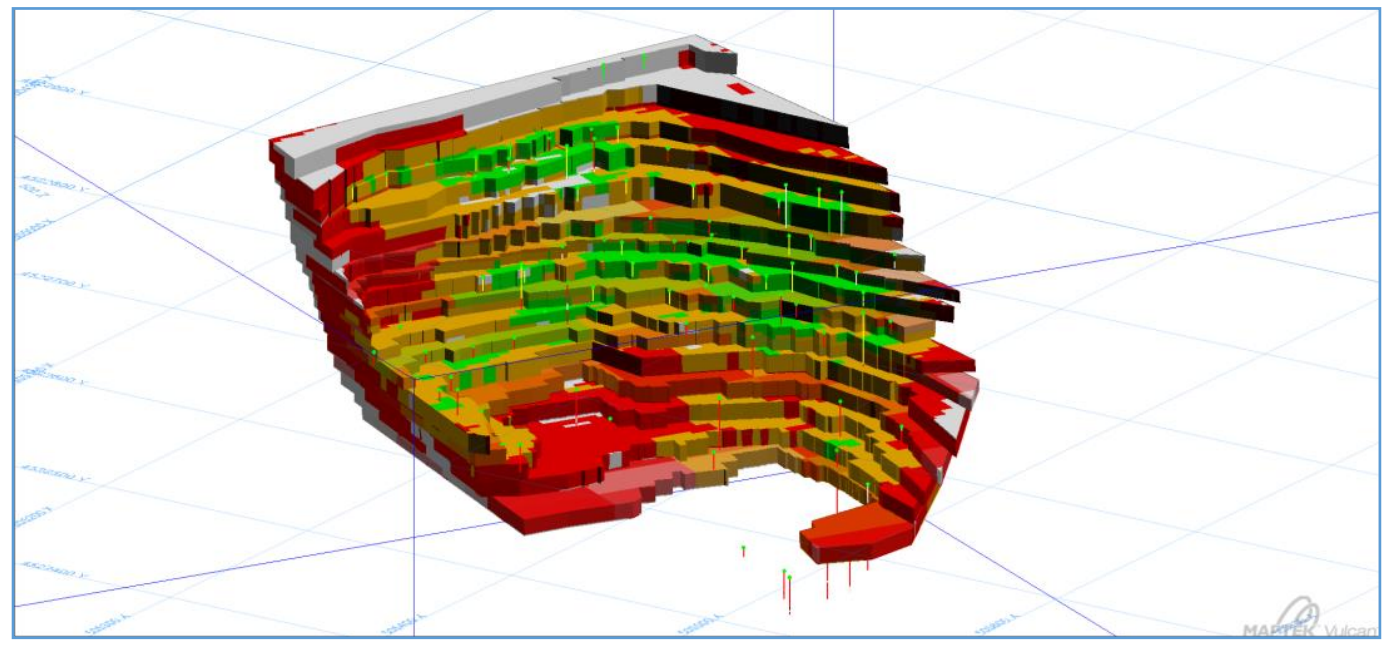

Figure 6 - Solid triangulation models of the final excavation benches of the Platanotopos quarry coloured by reserves classification $($ green $=$ proved reserves, orange $=$ probable reserves, red $=$ inferred resources).

This logic leaves out of the definition of initial quality the large scale tectonism (represented by a solidity field called SYNOXH), which affects the final quality after it is estimated separately with its own class fields. In other words, as with the different initial quality classes (A1, A2, etc.), a number of fields are defined for the different tectonism categories. The reason for handling tectonism separately is the different orientation of large scale tectonism requiring a different search ellipsoid orientation during estimation to the one used for all other fields. It is combined with initial qualities to derive the final ones with degrading wherever necessary based on the estimated value of this field.

In other words, if the original field SYNOXH (solidity) has a value of 1, then the field SN1_PR receives the value of 1 , if it has a value of 2, then field SN2_PR receives the value of 1 and so on. The original quality class fields and the additional tectonism field are combined after interpolation in space to receive 
the final qualities. The need to interpolate tectonism separately is due to its different spatial distribution, i.e. the different orientation of this parameter in space compared to other parameters.

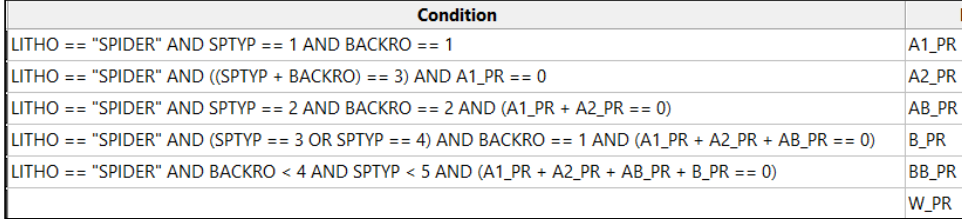

Figure 7 - Quality class fields calculation based on original colour, texture and fracture fields for the Platanotopos quarry.

After calculation of initial quality class fields and tectonism categories, a secondary process of the database is performed in order to calculate the location of each sample (XYZ coordinates at the centre of each sample) and assign a weighting factor to the samples. This factor takes the value of 1 if the sample is from a section on the face of the quarry, and 0.5 if the sample comes from a drillhole. Essentially, more weight is given to face sections as their quality assessment is performed on a surface larger than the drillholes and therefore better approaches the actual quality of the marble in the specific location. These weight factors are used to further weight samples during interpolation.

\subsection{Qualities Estimation}

Interpolation of quality class field values was performed using the inverse distance squared method as implemented by Maptek Vulcan Quarry Modeller software on the basis of a block model. The estimated volume is divided in blocks of the same size. For Platanotopos quarry, a block model with rotation around $\mathrm{Z}$ axis was constructed that covered the entire quarry volume and current sampling. The model specifications are given in Table 6 . Block dimensions were configured based on the marble volumes that are extracted separately at the given quarry. In each block, the percentage of each marble quality was estimated using the method analysed earlier using neighbouring samples. These samples are selected around each block using search ellipsoids which are oriented according to the geological features of the particular deposit.

Table 6 - Block model specifications of the Platanotopos quarry.

\begin{tabular}{|l|c|c|}
\hline \multirow{4}{*}{ Origin } & $\mathrm{X}$ & 505,460 \\
\cline { 2 - 3 } & $\mathrm{Y}$ & $4,522,340$ \\
\cline { 2 - 3 } & $\mathrm{Z}$ & 290.5 \\
\hline \multirow{3}{*}{ Model dimensions } & $\mathrm{X}$ & 582 \\
\cline { 2 - 3 } & $\mathrm{Y}$ & 728 \\
\cline { 2 - 3 } & $\mathrm{Z}$ & 350 \\
\hline \multirow{3}{*}{ Orientation } & $\mathrm{X}$ & 6 \\
\cline { 2 - 3 } & $\mathrm{Y}$ & 2.8 \\
\cline { 2 - 3 } & $\mathrm{Z}$ & 7 \\
\hline Block dimensions & $\mathrm{X}$-axis azimuth & 28 \\
\cline { 2 - 3 } & $\mathrm{X}$-axis rotation & 0 \\
\cline { 2 - 3 } & $\mathrm{Y}$-axis rotation & 0 \\
\hline
\end{tabular}

Ellipsoid parameters are given in Table 7. Block estimation in Platanotopos quarry was different to the other quarries as the ellipsoids had different orientation in each block due to the folding of the deposit. Thus, a special function of the software was used before estimation that calculates the appropriate ellipsoid orientation for each block, taking in to account reference surfaces that define folding (Figure 8). 
In the case of Iktinos Hellas SA quarries, the modifying factors for converting marble resources to reserves include the limitation of resources inside a technicallly feasible excavation as designed by the company's personnel (mining and legal factors), inside the exploitation license limits (legal, environmental and governmental factors). Classification based on the three categories of mineral resources was performed during three stages of block estimation, using ellipsoids of different dimensions and different sample count requirements (Table 7).

Table 7 - Platanotopos quarry estimation parameters.

\begin{tabular}{|l|c|c|c|c|}
\hline & $\begin{array}{c}\text { Measured } \\
\text { (Proved) } \\
\text { Reserves }\end{array}$ & $\begin{array}{c}\text { Indicated } \\
\text { (Probable) } \\
\text { Reserves }\end{array}$ & $\begin{array}{c}\text { Inferred } \\
\text { In-Pit } \\
\text { Resources }\end{array}$ & SYNOXH \\
\hline Major Axis (m) & 15 & 30 & 50 & 50 \\
\hline Semi-major Axis (m) & 15 & 30 & 50 & 50 \\
\hline Minor Axis (m) & 5 & 10 & 15 & 10 \\
\hline Azimuth & Variable & Variable & Variable & 330 \\
\hline Plunge & Variable & Variable & Variable & 0 \\
\hline Dip & Variable & Variable & Variable & 70 \\
\hline Minimum Number of Samples & 8 & 8 & 4 & 4 \\
\hline Maximum Number of Samples & 20 & 20 & 20 & 20 \\
\hline Maximum Samples per Drillhole & 4 & 4 & 4 & 4 \\
\hline Blocks estimated & 1342 & 9754 & 26259 & 37355 \\
\hline
\end{tabular}

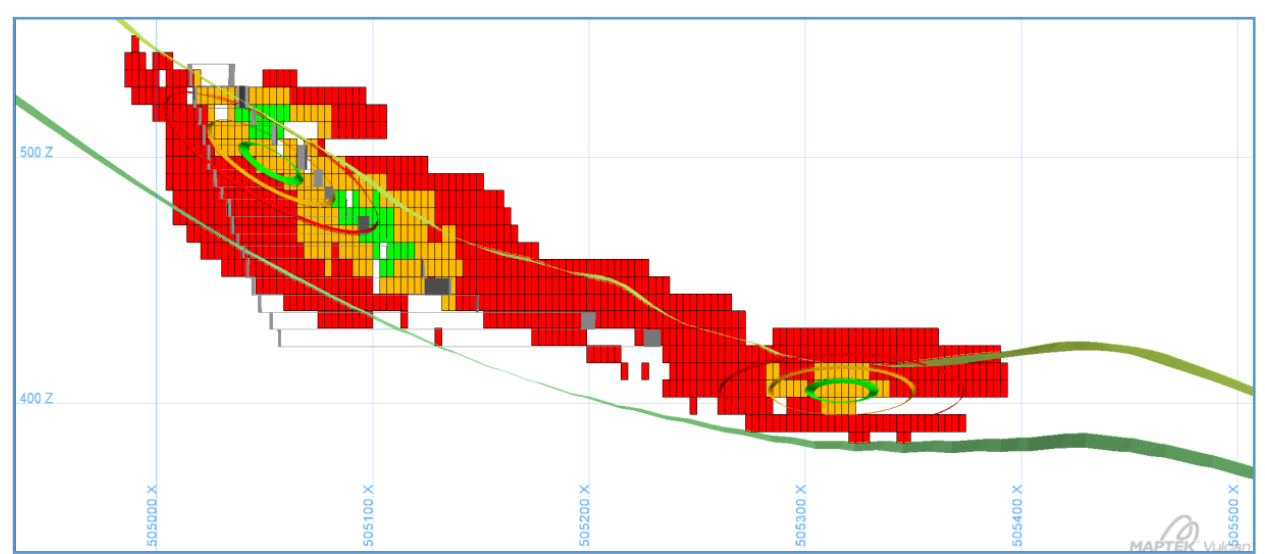

Figure 8 - Cross section through block model and resource classification ellipsoids following the deposit folding of the Platanotopos quarry (smaller to larger - measured, indicated, inferred).

\section{Results and Conclusions}

\subsection{Reserves Estimates}

Table 8 gives the results of the reserves calculation. For each reserve category, three generalised qualities are reported. Generalising of qualities was considered necessary as the limited sampling does not allow more detailed analysis of reserves to the original $\mathrm{A} 1, \mathrm{~A} 2, \mathrm{AB}, \mathrm{B}$, and $\mathrm{BB}$ qualities produced by the particular quarry. Therefore, reported quality A corresponds to quantities A1 and A2, AB is reported on its own, while $\mathrm{B}$ quality contains both $\mathrm{B}$ and $\mathrm{BB}$. Reported waste quantities are the remaining bench volume which cannot be estimated using the available sampling and the limitations 
set by the reserve categories as to ellipsoid dimensions and minimum sample count. As a result, a considerable part of the waste and the inferred resources can be upgraded potentially in the future with additional drilling which will provide a clearer picture in areas with no samples currently.

Table 8 - Reserves estimation results for the Platanotopos quarry.

\begin{tabular}{|c|c|c|c|c|c|c|c|c|c|c|c|c|}
\hline & & Measu & $\begin{array}{c}\text { (Proved } \\
\left(\mathbf{m}^{3}\right)\end{array}$ & eserves & Indicat & $\begin{array}{c}\text { Probab } \\
\left(\mathbf{m}^{3}\right)\end{array}$ & Reserves & $\overline{\text { Infer }}$ & $\begin{array}{c}\text { In-Pit I } \\
\left(\mathbf{m}^{3}\right)\end{array}$ & ources & & \\
\hline Bench & Elevation & $\overline{\mathbf{A}}$ & $\overline{\mathbf{A B}}$ & B & $\overline{\mathbf{A}}$ & $\overline{\mathrm{AB}}$ & B & $\bar{A}$ & $\overline{\mathbf{A B}}$ & B & Waste & Total \\
\hline P11 & 423 & 296 & 227 & 242 & 2,753 & 8,229 & 14,236 & 4,443 & 18,843 & 27,146 & 130,896 & 207,312 \\
\hline P10 & 430 & 140 & 128 & 337 & 3,942 & 7,863 & 12,088 & 7,094 & 19,414 & 41,562 & 92,659 & 185,228 \\
\hline P09 & 437 & 43 & 68 & 51 & 3,402 & 11,166 & 16,313 & 5,460 & 21,649 & 39,272 & 68,859 & 166,283 \\
\hline P08 & 444 & 28 & 156 & 708 & 2,078 & 13,171 & 25,174 & 4,088 & 16,381 & 34,392 & 59,047 & 155,222 \\
\hline P07 & 451 & 204 & 1,993 & 4,101 & 2,590 & 12,393 & 36,991 & 4,506 & 11,370 & 32,786 & 59,560 & 166,494 \\
\hline P06 & 459 & 336 & 1,548 & 4,253 & 2,444 & 7,987 & 24,850 & 2,485 & 5,618 & 12,518 & 31,392 & 93,432 \\
\hline P05 & 464 & 600 & 1,718 & 5,871 & 2,405 & 7,263 & 25,625 & 2,194 & 5,335 & 12,740 & 26,246 & 89,998 \\
\hline P04 & 469 & 722 & 2,351 & 9,020 & 2,116 & 7,906 & 30,162 & 2,530 & 6,826 & 18,035 & 30,793 & 110,460 \\
\hline P03 & 476 & 771 & 2,019 & 8,445 & 1,059 & 5,642 & 28,002 & 1,554 & 7,095 & 20,281 & 26,147 & 101,015 \\
\hline P02 & 483 & 398 & 1,031 & 4,824 & 465 & 2,732 & 18,544 & 573 & 5,367 & 16,006 & 18,327 & 68,267 \\
\hline P01 & 488 & 227 & 644 & 5,839 & 443 & 2,927 & 22,082 & 277 & 5,568 & 23,672 & 25,995 & 87,676 \\
\hline P00 & 495 & 1 & 826 & 5,230 & 358 & 2,691 & 28,704 & 177 & 5,356 & 29,298 & 38,795 & 111,435 \\
\hline P-01 & 505 & 165 & 818 & 3,063 & 343 & 2,376 & 20,618 & 104 & 3,624 & 18,147 & 22,949 & 72,207 \\
\hline P-02 & 513 & 118 & 253 & 2,536 & 298 & 2,012 & 11,791 & 134 & 2,634 & 17,007 & 14,016 & 50,801 \\
\hline $\mathbf{P - 0 3}$ & 520 & 17 & 19 & 192 & 198 & 1,022 & 14,530 & 82 & 1,034 & 10,987 & 20,008 & 48,090 \\
\hline P-04 & 529 & & & & - & 22 & 1,240 & 89 & 139 & 8,449 & 18,125 & 28,063 \\
\hline Total & & 4,068 & 13,801 & 54,713 & 24,894 & 95,402 & 330,951 & 35,790 & 136,251 & 362,299 & 683,814 & $1,741,983$ \\
\hline
\end{tabular}

\subsection{Conclusions}

This paper discussed a reserves estimation procedure applied at the Platanotopos marble quarry of Iktinos Hellas SA. Reserves estimation was performed using specialised software. Original sample quality values were converted to indicator values to allow interpolation to a block model using inverse distance weighting. This procedure provides Iktinos Hellas SA and potentially other marble quarrying companies with a solid method to produce reliable results according to international standards of resources/reserves reporting.

\section{References}

Abdollahisharif, J., Bakhtavar, E., Alipour, A. and Mokhtarian, M., 2012. Geological Modeling and Short-term Production Planning of Dimension Stone Quarries Based on Market Demand, Journal of Geological Society of India, 80, September 2012, 420-428.

Careddu, N., Siotto, G. and Tuveri, A., 2010. Evolution of a Marble Quarry: From Open Cast to Underground Exploitation, Proceedings of Global Stone Congress 2010, Alicante, Spain.

Forlani, G. and Pinto, L., 2000. Monitoring Marble Extraction in Open Cast Quarries, International Archives of Photogrammetry and Remote Sensing, XXXIII/B4, Amsterdam, 2000, 283-289.

Kapageridis, I., 2015. Iktinos Hellas SA Quarries - Marble Reserves Estimation Technical Report, September 2015, Maptek Pty Ltd. 